\title{
DETECTION IN SUBSURFACE AIR OF RADIOXENON RELEASED FROM MEDICAL ISOTOPE PRODUCTION
}

Christine Johnson*1, Steven Biegalski ${ }^{1}$, Derek Haas ${ }^{2}$, Justin Lowrey ${ }^{2}$, Theodore Bowyer ${ }^{2}$, James Hayes $^{2}$, Reynold Suarez ${ }^{2}$, Michael Ripplinger ${ }^{2}$ 


\begin{abstract}
In order to better understand potential backgrounds of Comprehensive-Nuclear Test-Ban Treaty on-site inspection relevant gases, a sampling campaign was performed near Canadian Nuclear Laboratories in the Ottawa River Valley, a major source of environmental radioxenon. First of their kind measurements of atmospheric radioxenon imprinted into the shallow subsurface from an atmospheric pressure driven force were made using current on-site inspection techniques.

Both atmospheric and subsurface gas samples were measured and analyzed to determine radioxenon concentrations. These measurements indicate that under specific sampling conditions, on the order of ten percent of the atmospheric radioxenon concentration may be measured via subsurface sampling.
\end{abstract}

\title{
Keywords
}

xenon; barometric pumping; medical isotope production; on-site inspection; CTBT; radionuclide detection

\section{Introduction}

The Comprehensive Nuclear-Test-Ban Treaty (CTBT) includes the ability for member states to request an On-Site Inspection (OSI) as part of the verification process. The purpose of an OSI is to gather local evidence of a possible nuclear event; the presence of radioactive noble gases, particularly radioxenon, is a primary indicator of recent nuclear activity and hence is relevant to an OSI. As a noble gas, xenon is chemically inert resulting in a relatively high leakage probability from an underground test and has previously been measured at the surface after a nuclear test (Carrigan et al., 1996; Dubasov, 2010; Schoengold et al., 1996). 
On-Site Inspections will include the option to employ both above ground and subsurface soil gas

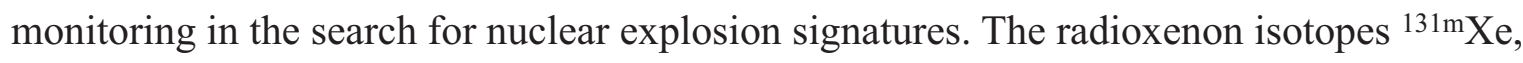

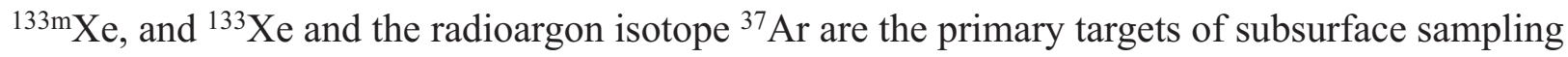
(Carrigan and Sun, 2014).

As advances in detector technology and analysis methods lead to lower detection limits, the presence of radioxenon from sources other than nuclear explosions, both natural and anthropogenic, becomes a complicating factor in the assessment of environmental samples. The current OSI capability for radioxenon detection is in the range of $1 \mathrm{mBq} / \mathrm{m}^{3}$ for ${ }^{133} \mathrm{Xe}$ using mobile measurement systems (Ringbom et al., 2015; Wieslander and Khrustalev, 2014). More significantly, in the case of low-level detection the presence of these sources may also bias the isotopic ratios used to discriminate significant events.

\section{Medical Isotope Production as a Radioxenon Source}

With an estimated total annual release of $\mathrm{Bq}$ of ${ }^{133} \mathrm{Xe}$, medical isotope production facilities are the most significant contributor to the global radioxenon background (Saey, 2009). While the current distribution of facilities has resulted in elevated concentrations primarily in the midlatitudes of the Northern Hemisphere, new facilities are causing an increased background level in certain Southern Hemisphere locations as well (Saey et al., 2010a; Wotawa et al., 2010). An additional complication is that the isotopic ratios of radioxenon released from medical isotope production may be similar to that of a nuclear explosion, specifically in facilities which use highly-enriched uranium targets (Saey et al., 2010b). Other sources of background radioxenon, 
including nuclear power plants and natural production, are more easily distinguished but they still serve to complicate the overall background (Hebel, 2010a; Saey et al., 2010b).

One of the largest producers of ${ }^{99}$ Mo globally is Canadian Nuclear Laboratories' Chalk River Laboratories in Ontario, Canada. At this facility, highly-enriched uranium targets are irradiated to produce ${ }^{99} \mathrm{Mo}$, which is then extracted on-site using chemical dissolution. During this dissolution process and the later cementing of the resultant waste, ${ }^{133} \mathrm{Xe}$ is released at an estimated rate of up to $10^{13} \mathrm{~Bq} /$ day (Saey, 2009).

\section{Imprinting}

Measurement of radioxenon during an OSI is heavily dependent on underground transport processes and the geology through which transport occurs (Carrigan et al., 1996; Carrigan and Sun, 2014; Lowrey et al., 2013, 2012).While transport in homogenous media may be dominated by diffusion at small scales, in fractured geologies barometric pumping is predicted to dominate the bulk movement of air (Nilson et al., 1991). Barometric pumping involves changes in atmospheric pressure acting to impress or withdraw gas from the subsurface, with it generally resulting in an increase in the rate of vertical mixing of air in the subsurface (Carrigan and Sun, 2011; Lowrey, 2013). Because trace gas lost to the atmosphere is not replaced, barometric pumping primarily acts as an upward transport mechanism for signatures of underground nuclear explosions. However, it is predicted that barometric pumping may have an additional effect of driving atmospheric gas into the shallow subsurface, which is the realm of an OSI. Simulations have shown that during periods of increasing barometric pressure, detectable quantities of atmospheric radioxenon could potentially be imprinted into the shallow subsurface (Carrigan and 
Sun, 2014; Lowrey, 2013; Lowrey et al., 2015a, 2012). This process can both serve to contaminate the soil-gas environment if a plume of radioactive noble gas passes over sampling locations, which could complicate the interpretation of radioxenon detections in an OSI, but it could also dilute potential signature-containing subsurface air with atmospheric, thus reducing concentrations of the gases being measured.

In order to validate the predictions of imprinting, a sampling campaign was performed near the Canadian Nuclear Laboratories medical isotope production facility, the world's largest source of atmospheric ${ }^{133} \mathrm{Xe}$. An analysis of the stack release data and atmospheric transport of the radioxenon released from this site can be found in Johnson, et al (Johnson et al., 2015a).

\section{Infilltration}

Another method by which atmospheric intrusion might occur is through infiltration. This differs from imprinting only in the method by which the atmospheric gas is introduced to the subsurface. While the term imprinting implies the natural process of barometric pumping, infiltration signifies that the atmospheric gas was drawn into the subsurface by the sampling process. This infiltration could be the result of a poorly sealed hole which allows atmospheric air to be drawn directly into the subsurface sample through the hole itself. However, assuming a well-sealed sampling hole, the main source of infiltration is assumed to be due to the sampling process itself. Samples are obtained by continuously pumping on a single point for 12-24 hours, creating a substantial pressure drop and subsequent flow of gas from the surrounding subsurface area. This can also serve to pull atmospheric gas into the subsurface, acting almost as an enhanced imprinting mechanism (Lowrey et al., 2015a). 


\section{Experimental}

From 10-19 September 2014, daily air samples were collected from both above-ground (atmospheric) and from the subsurface. While previous work had been performed to select an ideal sampling location (Johnson et al., 2015b), complications led to the need to choose an alternate site upon arrival. The site utilized was a clearing in Sheenboro, Quebec, $14 \mathrm{~km}$ southeast of the Canadian Nuclear Laboratories medical isotope production stack; the locations of both the sampling site and the stack are shown in Figure 1. This site was co-located with a permanently emplaced $\mathrm{NaI}(\mathrm{Tl})$ detector belonging to Health Canada as part of their fixed-point surveillance network (Grasty et al., 2001).

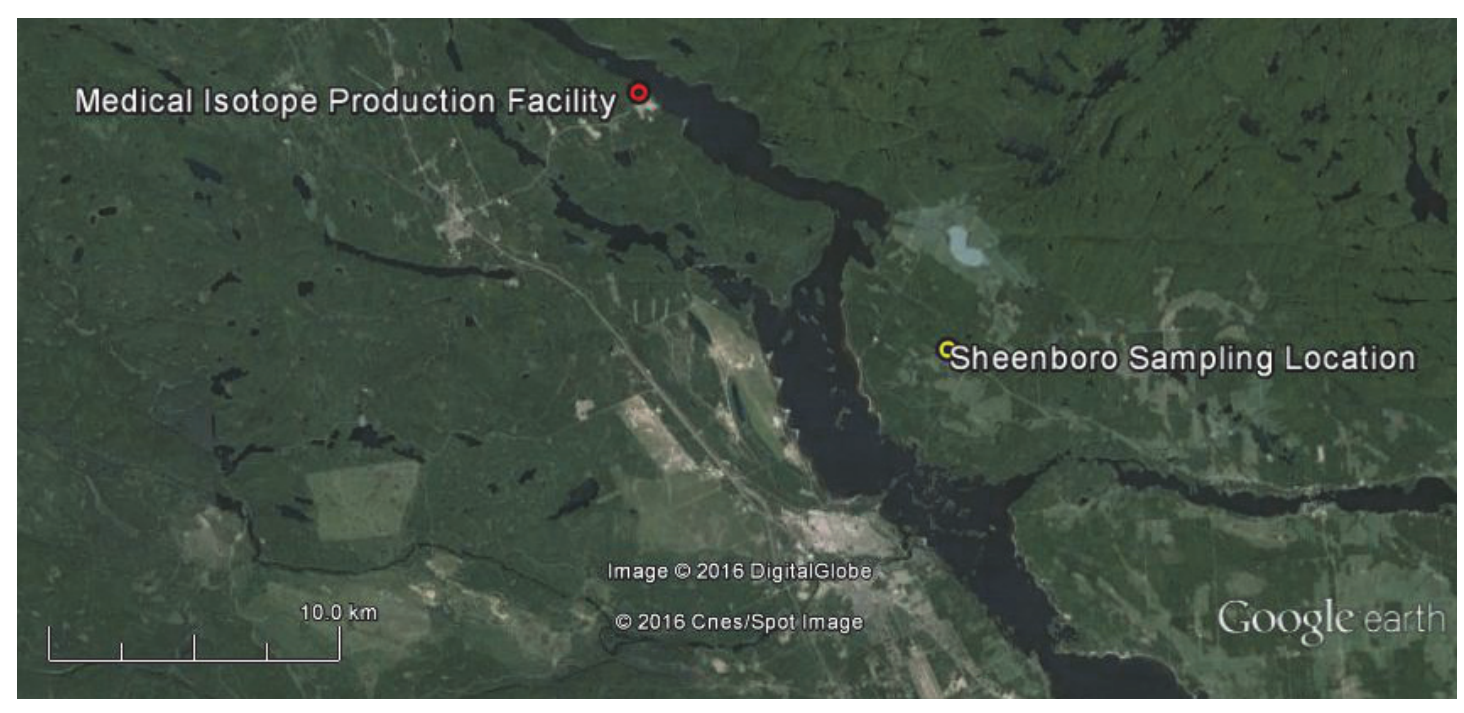

Figure 1: A map showing the location of the Sheenboro sampling location relative to the medical isotope production facility at Canadian Nuclear Laboratories.

\subsection{The Hole}

The sampling hole was drilled using a 2 -in auger to a depth of $0.90 \mathrm{~m}$. A screen was then attached to sampling tubing and lowered to the bottom of the hole, which was then backfilled with the 
removed soil to a depth of $0.49 \mathrm{~m}$. It was then verified that this backfill completely covered the screen at the bottom of the hole. The remainder of the hole was filled with a bentonite mixture which consisted of a mixture of 1 part bentonite to 4 parts water. The bentonite was then capped with construction grade sand. A top view of the completed sampling hole can be seen in Figure 2.

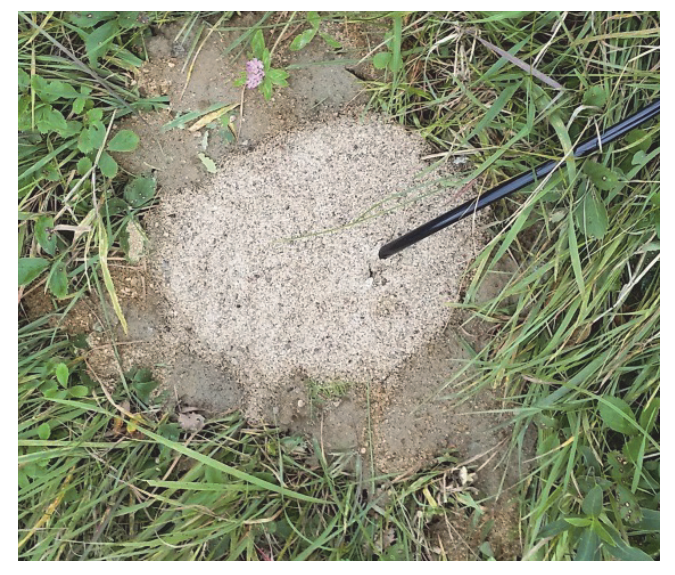

Figure 2: The sealed sampling hole where the subsurface samples were collected.

\subsection{The Sampler}

Subsurface gas sampling was carried out using a Sub-Surface Gas Sampler (SSGS) designed and built by Pacific Northwest National Laboratory (PNNL). The sampler was programmed to provide a constant flow rate to the collection bags over the sampling period. Within the sampler, a small fraction of the air was diverted to a Durridge RAD7 radon detector that integrated measurements of the radon concentration in the sampled air in intervals of five minutes. Additionally, the SSGS contained a barometer to measure local atmospheric pressure as well as humidity and temperature sensors. 


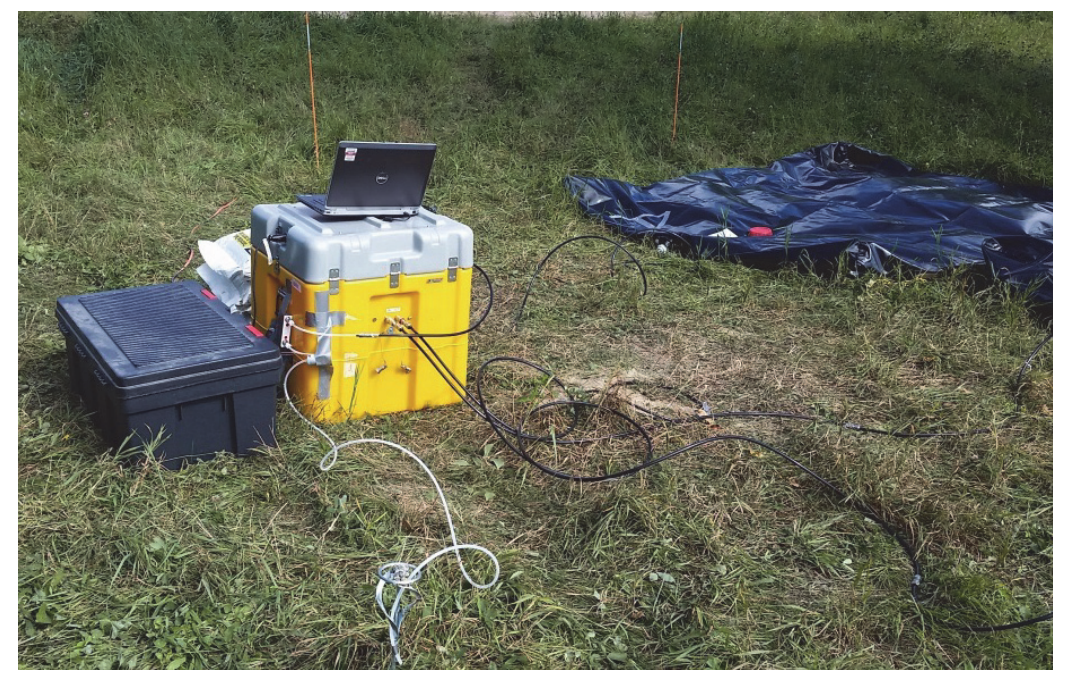

Figure 3: Experimental setup of the sampling location in Sheenboro, QC. The black sample bags are shown in the upper right, with the SSGS contained within the yellow crate and batteries providing power to the sampler in the black crate. The subsurface sampling hole is just off the bottom right corner of the photo and the atmospheric sample location is the silver stake in the bottom left.

\subsection{Sample Collection}

Samples of the atmospheric air at ground level were collected simultaneous to subsurface sampling. A sampling tube was emplaced just above ground level, pointed downward to prevent water from entering the system in case of rain. The tubing was then connected to a separate pump which was set to the same flow rate (generally $1.3-1.5 \mathrm{~L} / \mathrm{min}$ ) as that of the subsurface gas sampler and fed into a separate sample collection bag. The setup is shown in Figure 4 with arrows indicating the general direction of flow. The atmospheric bag was marked to distinguish it from the subsurface sample bag to prevent cross-contamination in case of any memory effect in the bag. 


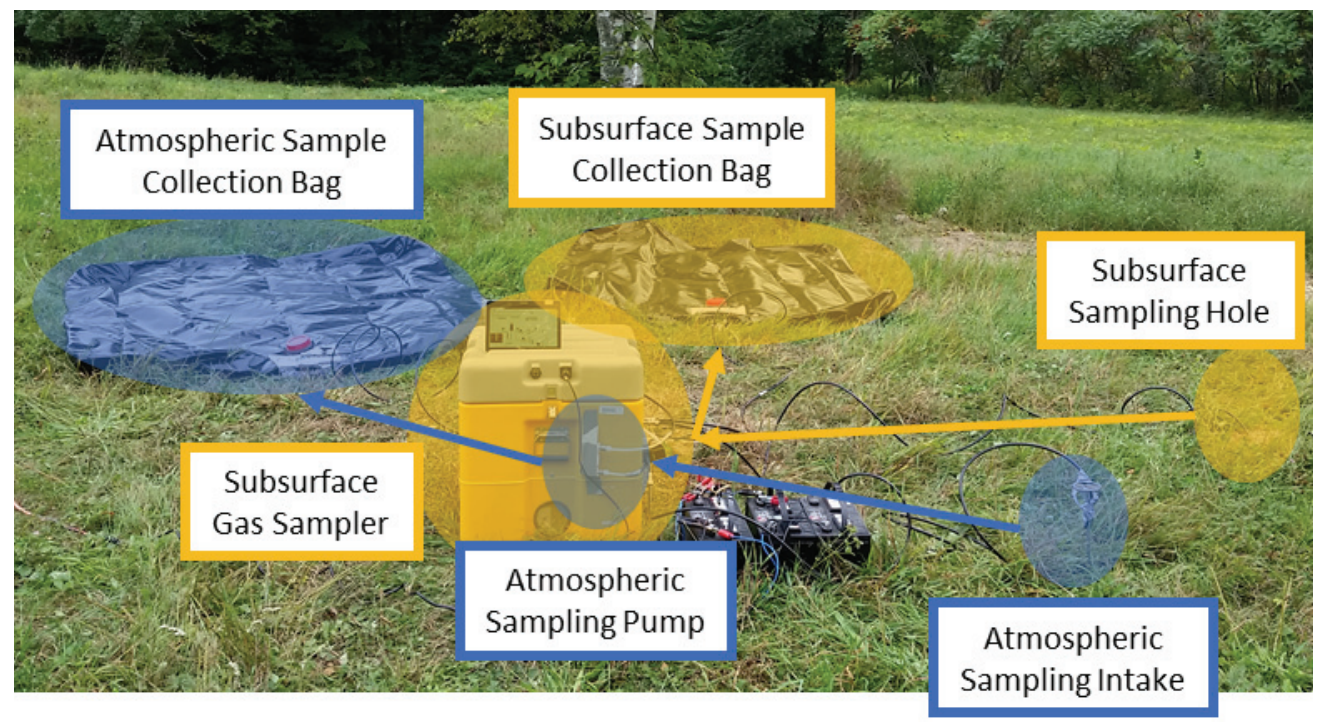

Figure 4: Sheenboro site setup with the various sampling steps highlighted in blue for the

atmospheric sampler, or yellow for the subsurface sampler. The RAD7 samples follow the same first two steps as the subsurface samples, but the waste gas is vented rather than stored.

The gas samples were collected inside a $2 \mathrm{~m}^{3}$ grey water bag during sampling. Both bags were placed 3-4 meters away from the sampling hole to avoid acting as a seal on the atmospheresubsurface interface. After the sampling period, the samples were removed from the collection bags and compressed into scuba bottles at pressures ranging from 1000-2500 psi for transport, a process which generally took 20-30 minutes. During compression, the subsurface samples were always compressed first in an effort to limit any potential memory effects (i.e., cross contamination between samples) within the compressor. The times of compression were also notated for future comparison with $\mathrm{NaI}(\mathrm{Tl})$ measurements of atmospheric radioxenon concentrations. 


\subsection{Sample Analysis}

Gas samples were shipped to PNNL for radioxenon analysis in two batches. Analysis was performed using chemical separation of xenon from the bulk air and subsequent beta-gamma coincidence spectroscopy of the purified xenon gas (Bowyer et al., 2002). ${ }^{133} \mathrm{Xe}$ was detected in all analyzed samples, however, due to the delay between sample collection and analysis it was not possible to determine the ${ }^{135} \mathrm{Xe}$ (half-life $9.14 \mathrm{~h}$ ) concentration in the samples.

\section{Results and Discussion}

The results of the sampling campaign are shown in Table 1 and Figure 6. In Figure 6, the ${ }^{133} \mathrm{Xe}$ concentrations for both the atmospheric and subsurface samples are shown, as is the measured ${ }^{133} \mathrm{Xe}$ from the co-located $\mathrm{NaI}(\mathrm{Tl})$ detector. For much of the sampling period, the measured subsurface concentrations of ${ }^{133} \mathrm{Xe}$ were on the order of $1 \mathrm{mBq} / \mathrm{m}^{3}$. Measurements performed on soil samples from the sampling holes indicate a low concentration of natural uranium in the soil $(0.79 \mathrm{ppm})$ making it unlikely that these ${ }^{133} \mathrm{Xe}$ concentrations were heavily influenced by natural production via the spontaneous fission of ${ }^{238} \mathrm{U}$ (Hebel, 2010b). Rather, this seems to indicate some retention of ${ }^{133} \mathrm{Xe}$ in the subsurface, likely from both past plume passages and the consistently elevated atmospheric concentration of ${ }^{133} \mathrm{Xe}$ across the region.

While both the measured subsurface and atmospheric radioxenon concentrations are consistently low during the first half of the sampling period, the passage of a plume on 16 September results in a clearly elevated atmospheric concentration. The corresponding subsurface sample for that date was lost during processing, however, a clearly elevated subsurface concentration can be observed on the following days while the atmospheric concentrations returned immediately to 
their minimal value. If the elevated subsurface concentrations were errantly caused by atmospheric radioxenon contamination in the sample we would expect to have seen this occur in earlier samples taken during a period with a similar atmospheric radioxenon concentration.

Additionally, if negative subsurface pressure was pulling significant quantities of atmospheric air into the collected samples then we would not expect to see the consistently elevated subsurface concentrations of ${ }^{133} \mathrm{Xe}$ which occurred even when atmospheric concentrations were significantly lower (i.e. samples collected 14-15 September).

Table 1: ${ }^{133}$ Xe concentrations for both subsurface and atmospheric gas samples over each sampling period and the corresponding 1-sigma uncertainties at the 95\% confidence limit. Concentrations marked with "- " indicate that a concentration is not available for that sample due to inability to collect or process the sample. The net pressure change over the sampling period is also given.

\begin{tabular}{lc|cc|cc}
\hline & & \multicolumn{2}{|c}{ Subsurface } & \multicolumn{2}{|c}{ Atmospheric } \\
\cline { 2 - 5 } Sampling Period & $\begin{array}{c}\text { Pressure Change } \\
{[\mathrm{mbar}]}\end{array}$ & $\begin{array}{c}133 \text { Xe Concentration } \\
{\left[\mathrm{Bqm}^{-3}\right]}\end{array}$ & $\begin{array}{c}133 \text { Xe Concentration } \\
{\left[\mathrm{Bqm}^{-3}\right]}\end{array}$ \\
\hline 9/10 18:19 - 9/11 11:22 & -17.652 & 1.109 & 0.128 & - & - \\
$9 / 1316: 16-9 / 1318: 26$ & -0.600 & 0.647 & 0.081 & - & 0.179 \\
$9 / 1323: 24-9 / 1415: 24$ & 5.385 & 0.693 & 0.077 & 1.607 & 0.035 \\
$9 / 1418: 47-9 / 1516: 21$ & -7.247 & 0.486 & 0.054 & 0.193 & 1.355 \\
$9 / 1517: 15-9 / 1615: 55$ & -2.703 & - & - & 0.554 & 0.052 \\
$9 / 1617: 18-9 / 1715: 42$ & -0.931 & 2.667 & 0.289 & 0.395 & 0.059 \\
$9 / 1716: 57-9 / 1815: 50$ & 9.088 & 1.375 & 0.152 & 0.153 & 0.797 \\
$9 / 1817: 08-9 / 1916: 24$ & 6.240 & 1.068 & 0.119 & 0.092 \\
\hline
\end{tabular}


The hole seal was monitored using the concentration of radon in the sampled air. If the seal was broken and substantial quantities of atmospheric air were making their way directly into the subsurface samples, then the radon concentration would be expected to decrease significantly. However, as seen in Figure 5, the average radon concentration shows a daily cycle which remains fairly consistent throughout the sampling period, only significantly varying when a major atmospheric pressure change occurs, and never decreases below approximately 4,000 Bq/ $\mathrm{m}^{3}$. This indicates that the hole can be considered to have remained sealed for the duration of the sampling campaign.

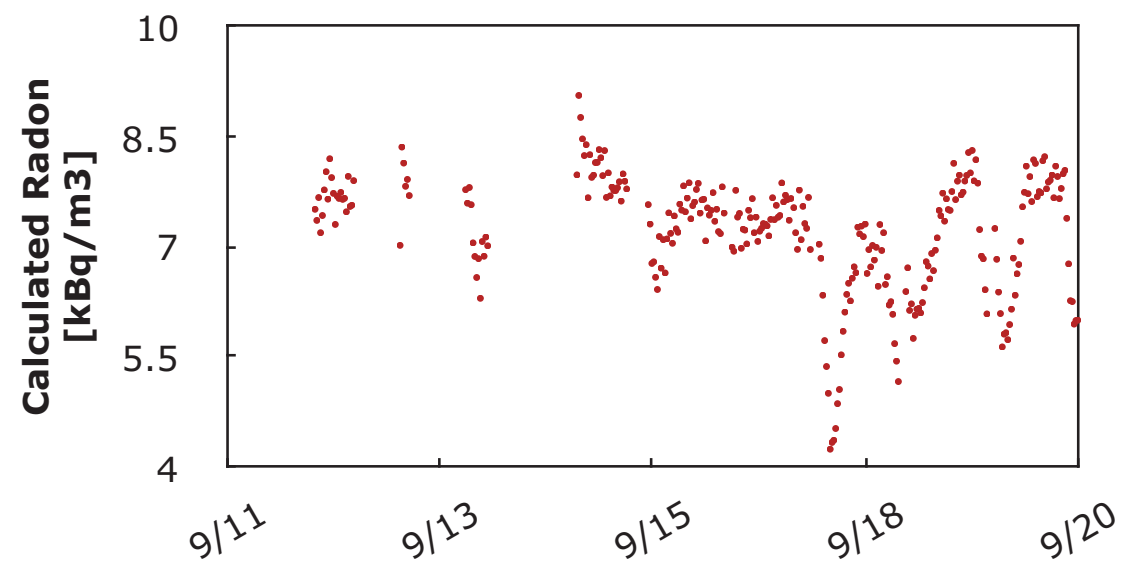

Figure 5: Concentrations of radon as measured via a RAD7 radon detector pulling air samples directly from the subsurface sampling line. Points are separated by 30 minute intervals.

As mentioned above, the subsurface and atmospheric samples were always compressed in an alternating fashion, with the subsurface sample compressed first then the atmospheric samples. Had there been an appreciable cross-contamination in the compressor, we would expect to see an elevated xenon concentration in both atmospheric and subsurface samples. However, the samples compressed on 17-18 September were found to contain much lower atmospheric xenon 
concentrations than the corresponding subsurface samples, indicating subsurface retention of radioxenon from the plume that passed over the area on 16 September.

It is worth noting that no samples, either subsurface or atmospheric, were below detection limits of the system even after decay during transport and processing. This indicates that in locations with regular large releases of radioxenon there may be a longer-term imprinted gas memory effect within the subsurface gas that results in a consistently elevated atmospheric radioxenon background. 

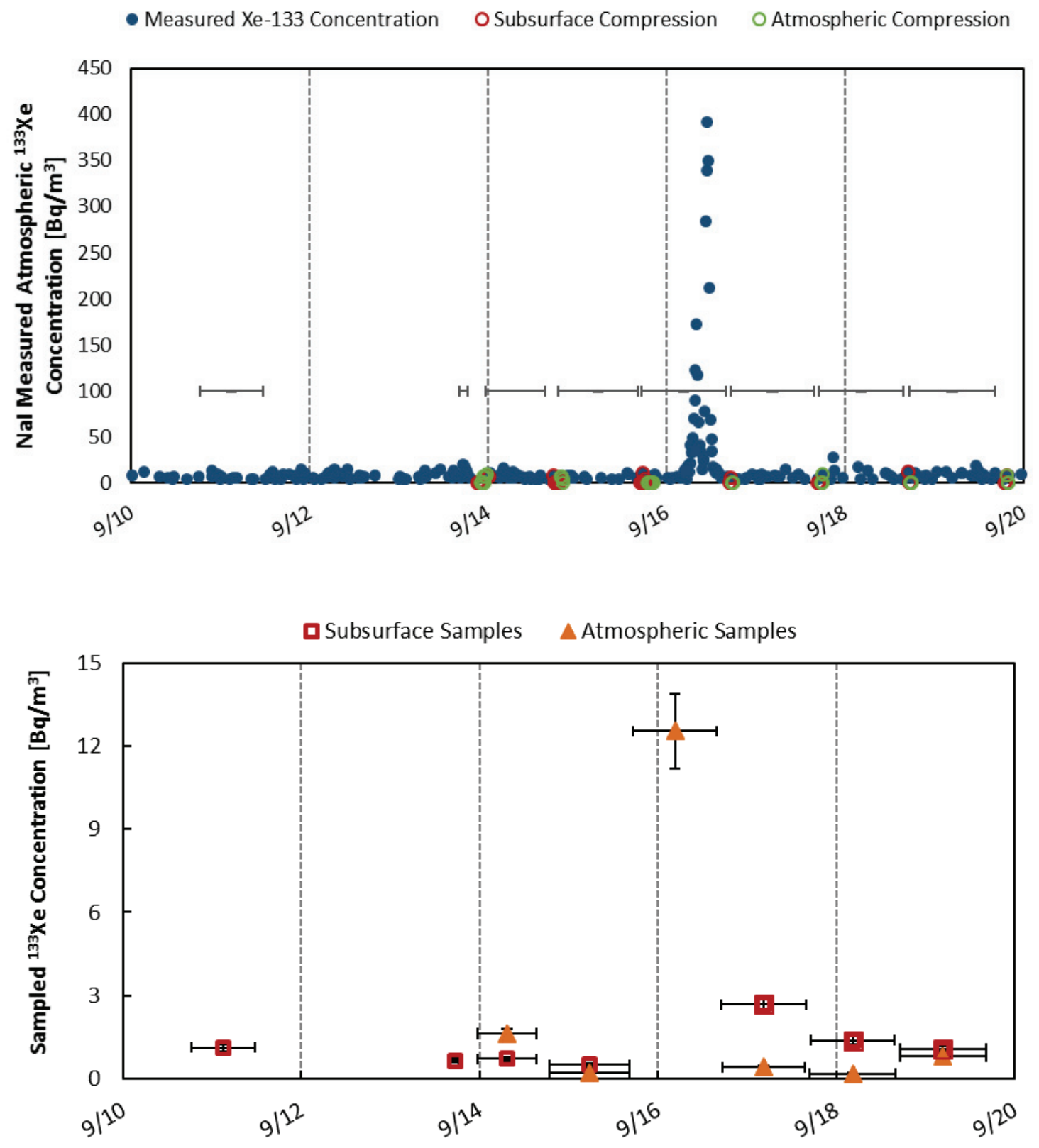
Figure 6: In the top half of the figure the blue points represent the NaI(Tl) measured atmospheric concentrations of ${ }^{133} \mathrm{Xe}$. Points with an outer circle indicate the times at which the samples were compressed into SCUBA bottles and which sample type was compressed. The bars span the sample collection periods. The bottom half of the figure presents the atmospheric and subsurface sample concentrations (triangles and hollow squares) along with their associated uncertainties (vertical error bars). The horizontal error bars represent the duration of the sampling period.

Figure 7 shows the atmospheric pressure during the entire sampling campaign as measured onsite by the barometer in the SSGS. It is interesting to note in Table 1 that the pressure change over the entire sampling period when the large radioxenon plume passes the site is negative, however during the shorter time period of the plume passage the barometric pressure increased by nearly 0.6 mbar (highlighted in orange in Figure 7). This might suggest that while long term pressure increases may be predicted to drive the overall barometric pumping mechanism, a short term increase during plume passage can very rapidly drive the imprinting process to the point where measurable quantities of radioxenon can be sampled days after plume passage. This could also indicate that pressure fluctuations are not the primary driving factor and that a competing process such as diffusion could dominate during plume passages. Future work will leverage transport models to explore the competing factors at work here. 
- Atmospheric Pressure

- Atmospheric Samples

- Subsurface Samples

- Series4

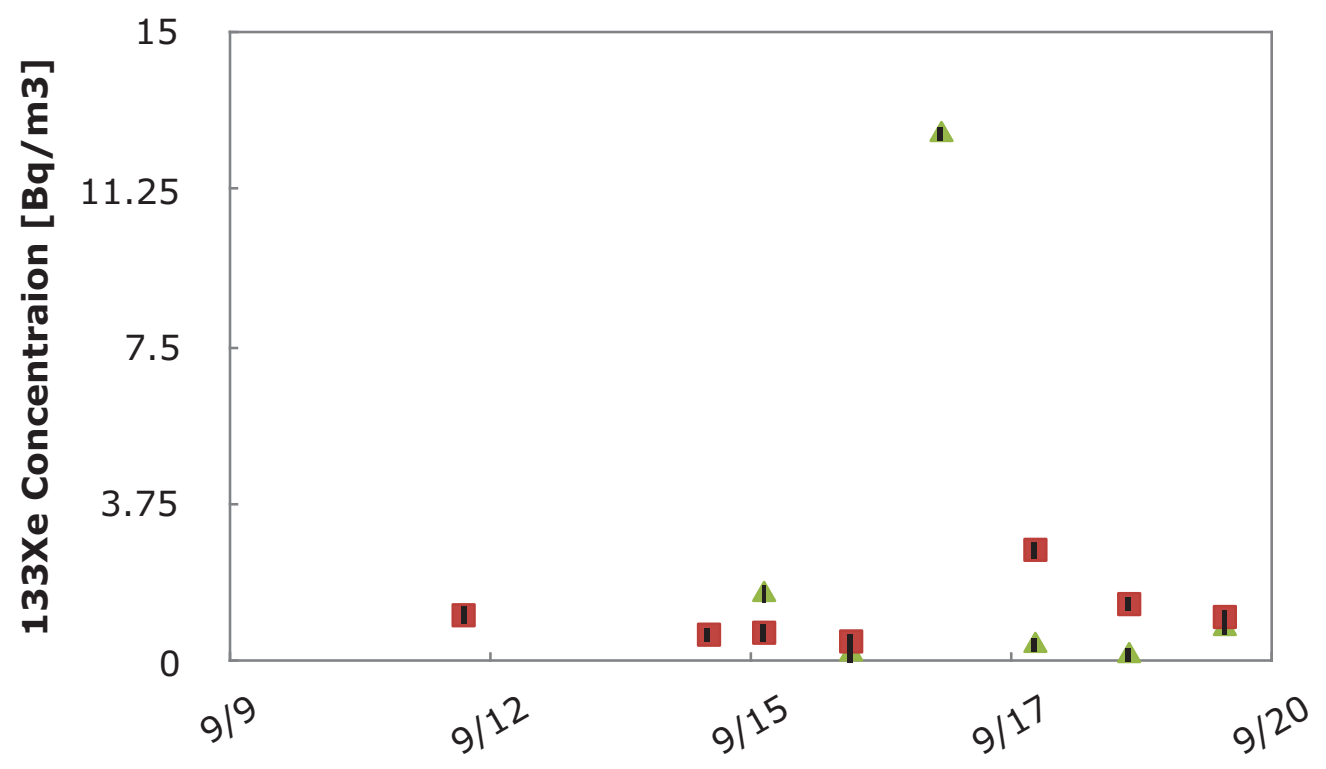

Figure 7: Barometric pressure [mbar] as measured by the subsurface sampling system during sampling periods. Measured values are shown by the blue points with the extrapolated pressure shown by the black line. Missing values correspond to periods when the sampling system was shut down. ${ }^{133}$ Xe concentrations of each sample are shown with the horizontal bars representing the sampling period for each sample. 
In Figure 8, the concentration of ${ }^{133} \mathrm{Xe}$ is projected forward from the sample collected on 17 September assuming that the only loss mechanism is radioactive decay. The projected concentrations are significantly higher than the measured concentrations, indicating that other processes must dominate radioxenon removal in the days after imprinting occurs. While the data is not conclusive, it should be noted that the initial significant loss of radioxenon from the subsurface system occurs during a period of steady or decreasing pressure, while during the subsequent pressure increase the loss rate noticeably decreases. Further modeling of this system will be useful in understanding how large of an effect pressure fluctuations have on the system and how much diffusion may play a role in xenon removal as well.

- Subsurface Samples — - Decay Only

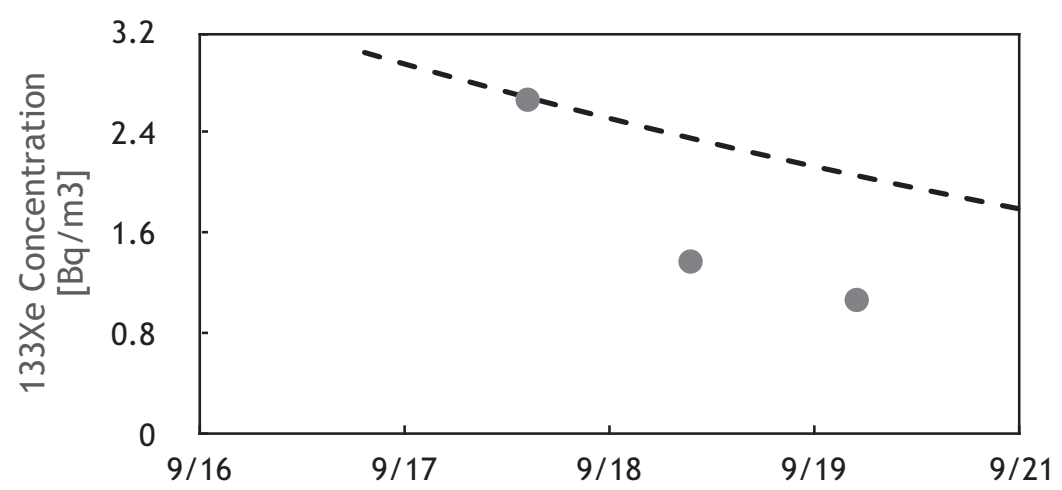

Figure 8: Points indicate the measured concentration in subsurface samples taken after the passage of an atmospheric radioxenon plume. The dashed line shows the predicted xenon concentrations assuming decay is the only loss mechanism.

\section{Conclusions}


The results of this sampling campaign are the first ever measurements of atmospheric radioxenon gas imprinted into the subsurface environment. While the data set is limited, these results suggest that under these weather conditions in an area of regular radioxenon releases a sampler located at approximately one meter in depth in sandy soil with no tarping to limit barometric influence could potentially detect levels of radioxenon on the order of $10 \%$ of the atmospheric radioxenon concentration. When we consider that this was not a worst case scenario as is often considered in simulations, then this result is consistent with simulated predictions (Carrigan and Sun, 2014; Lowrey et al., 2015b) . Additionally, it was shown that the elevated atmospheric concentration need not be a sustained condition for significant imprinting to occur, but can instead be in the form of a shorter transient plume during a time of increasing atmospheric pressure. Elevated levels of subsurface radioxenon are observed to persist for days after plume passage, but further work is clearly needed to understand how much time must pass after passage of a plume before the radioxenon drops below detectable levels.

\section{Acknowledgements}

The authors would like to thank Ed Korpach and Kurt Ungar of Health Canada for providing access to the Fixed Point Surveillance Network dose data, as well as their assistance in developing the Chalk River Laboratories sampling campaign. The authors would also like to thank George Dolinar, Adrienne Ethier, and Doug Killey of Canadian Nuclear Laboratories for their assistance in coordinating the sampling campaign.

This material is based upon work supported by the U.S. Department of Defense, Defense Threat Reduction Agency under Grant Number HDTRA1-12-1-0018. 


\section{References}

Bowyer, T.W., Schlosser, C., Abel, K.H., Auer, M., Hayes, J.C., Heimbigner, T.R., McIntyre, J.I., Panisko, M.E., Reeder, P.L., Satorius, H., Schulze, J., Weiss, W., 2002. Detection and analysis of xenon isotopes for the comprehensive nuclear-test-ban treaty international monitoring system. J. Environ. Radioact. 59, 139-51.

Carrigan, C., Heinle, R., Hudson, G.B., Nitao, J., Zucca, J., 1996. Trace gas emissions on geological faults as indicators of underground nuclear testing. Nature 382, 528-531.

Carrigan, C., Sun, Y., 2011. Issues Involving The OSI Concept of Operation For Noble Gas Radionuclide Detection (No. LLNL-TR-467731).

Carrigan, C.R., Sun, Y., 2014. Detection of Noble Gas Radionuclides from an Underground Nuclear Explosion During a CTBT On-Site Inspection. Pure Appl. Geophys. 171, 717-734. doi:10.1007/s00024-012-0563-8

Dubasov, Y. V., 2010. Underground nuclear explosions and release of radioactive noble gases. Pure Appl. Geophys. 167, 455-461. doi:10.1007/s00024-009-0026-Z

Grasty, R.L., Hovgaard, J., LaMarre, J.R., 2001. A fence line noble gas monitoring system for nuclear power plants. Radiat. Prot. Dosimetry 95, 249-56.

Hebel, S., 2010a. Genesis and Equilibrium of Natural Lithospheric Radioxenon and its Influence on Subsurface Noble Gas Samples for CTBT On-site Inspections. Pure Appl. Geophys. 167, 463-470. doi:10.1007/s00024-009-0037-9

Hebel, S., 2010b. Genesis and Equilibrium of Natural Lithospheric Radioxenon and its Influence on Subsurface Noble Gas Samples for CTBT On-site Inspections. Pure Appl. Geophys. 167, 463-470. doi:10.1007/s00024-009-0037-9

Johnson, C., Lowrey, J., Biegalski, S., Haas, D., 2015a. Examination of local atmospheric transport of radioxenon in the Ottawa River Valley. J. Radioanal. Nucl. Chem. 1-5. doi: $10.1007 / \mathrm{s} 10967-015-4488-4$

Johnson, C., Lowrey, J., Biegalski, S., Haas, D., 2015b. Regional transport of radioxenon released from the Chalk River Laboratories medical isotope facility. J. Radioanal. Nucl. Chem. doi:10.1007/s10967-015-4077-6

Lowrey, J.D., 2013. Subsurface Radioactive Gas Transport and Release Studies using the UTEX Model. The University of Texas at Austin.

Lowrey, J.D., Biegalski, S.R., Bowyer, T.W., Haas, D.A., Hayes, J.C., 2015a. Consideration of impact of atmospheric intrusion in subsurface sampling for investigation of suspected underground nuclear explosions. J. Radioanal. Nucl. Chem. doi:10.1007/ s10967-015-4462-1

Lowrey, J.D., Biegalski, S.R., Deinert, M.R., 2012. UTEX modeling of radioxenon isotopic fractionation resulting from subsurface transport. J. Radioanal. Nucl. Chem. 296, 129-134. doi:10.1007/s10967-012-2026-1 
Lowrey, J.D., Biegalski, S.R., Osborne, a. G., Deinert, M.R., 2013. Subsurface mass transport affects the radioxenon signatures that are used to identify clandestine nuclear tests. Geophys. Res. Lett. 40, 111-115. doi:10.1029/2012GL053885

Lowrey, J.D., Eslinger, P.W., Haas, D.A., Miley, H.S., 2015b. A consideration of radionuclide particulate resuspension as a verification tool in the CTBT On-Site Inspection verification component. J. Radioanal. Nucl. Chem. doi:10.1007/s10967-015-4554-y

Nilson, R.H., Peterson, E.W., Lie, K.H., Burkhard, N.R., Hearst, J.R., 1991. Atmospheric pumping: A mechanism causing vertical transport of contaminated gases through fractured permeable media. J. Geophys. Res. 96, 933-948.

Ringbom, A., Axelsson, A., Aldener, M., Fritioff, T., Kastlander, J., 2015. SAUNA III - a major upgrade, in: CTBT: Science and Technology 2015 Conference (SnT2015).

Saey, P.R.J., 2009. The influence of radiopharmaceutical isotope production on the global radioxenon background. J. Environ. Radioact. 100, 396-406. doi:10.1016/j.jenvrad. 2009.01.004

Saey, P.R.J., Auer, M., Becker, A., Hoffmann, E., Nikkinen, M., Ringbom, A., Tinker, R., Schlosser, C., Sonck, M., 2010a. The influence on the radioxenon background during the temporary suspension of operations of three major medical isotope production facilities in the Northern Hemisphere and during the start-up of another facility in the Southern Hemisphere. J. Environ. Radioact. 101, 730-8. doi:10.1016/j.jenvrad.2010.04.016

Saey, P.R.J., Bowyer, T.W., Ringbom, A., 2010b. Isotopic noble gas signatures released from medical isotope production facilities--simulations and measurements. Appl. Radiat. Isot. 68, 1846-54. doi:10.1016/j.apradiso.2010.04.014

Schoengold, C.R., DeMarre, M.E., Kirkwood, E.M., 1996. Radiological effluents released from U.S. Continental tests 1961 through 1992 317, 304. doi:DOE/NV-317 (Rev.1)

Wieslander, J.S.E., Khrustalev, K., 2014. Noble Gas Sampling and Detection Methods for OnSite Inspections in Support of CTBT. IAEA Symp. 2014.

Wotawa, G., Becker, A., Kalinowski, M., Saey, P., Tuma, M., Zähringer, M., 2010. Computation and analysis of the global distribution of the radioxenon isotope 133Xe based on emissions from nuclear power plants and radioisotope production facilities and its relevance for the verification of the nuclear-test-ban treaty. Pure Appl. Geophys. 167, 541-557. doi:10.1007/ s00024-009-0033-0 